\title{
RELIABLE GEAR DESIGN: TRANSLATION OF THE RESULTS OF SINGLE TOOTH BENDING FATIGUE TESTS THROUGH THE COMBINATION OF NUMERICAL SIMULATIONS AND FATIGUE CRITERIA
}

\author{
FRANCO CONCLI $^{1}$, LORENZO MACCIONI $^{1} \&$ LUCA BONAITI $^{2}$ \\ ${ }^{1}$ Faculty of Science and Technology, Free University of Bolzano, Italy \\ ${ }^{2}$ Department of Mechanical Engineering, Politecnico di Milano, Italy
}

\begin{abstract}
Establishing the actual gear root bending strength is a fundamental aspect in gear design. With this respect, gears materials can be characterized through two types of tests, i.e. on Running Gears (RG) or Single Tooth Bending Fatigue (STBF). The former is able to reproduce the loading conditions of the actual gears and, therefore, leads to the most accurate results. The latter excels in terms of efficiency and simplicity of the experimental campaign but as a drawback, tends usually to overestimate the material strength due to the different stress state histories it induces on the tooth root. Therefore, a common practice is to carry out STBF tests and apply a correction coefficient $\left(f_{\text {korr }}\right)$ for exploiting the results in the design of actual gears. In the present paper, an approach to estimate $f_{k o r r}$ centered on the combination of numerical simulations and multi-axial fatigue criteria based on the critical plane capable of taking into account non-proportional loading conditions has been proposed. In particular, the same gear geometry has been simulated through Finite Element (FE) models in two conditions, i.e. STBF and RG. The outcomes of the simulations, in terms of stress histories in the tooth root region, have been analyzed with five different fatigue criteria, i.e. Findley, Matake, McDiarmid, Papadopoulos, and Susmel et al. $f_{\text {korr }}$ has been calculated as the ratio between the maximum damage parameter observed in the STBF and RG conditions according to the different fatigue criteria. Results show that $f_{\text {korr }}$, calculated for three different materials (i.e. $18 \mathrm{NiCrMo} 5,42 \mathrm{CrMoS} 4,31 \mathrm{CrMo} 12$ ), differs up to $22 \%$ between the RG and the STBF conditions (depending on the criterion considered). Therefore, future studies should aim to understand which fatigue criterion is the most appropriate for this type of analysis. Keywords: material characterization, STBF, FEM, gears, multiaxial fatigue, critical plane.
\end{abstract}

\section{INTRODUCTION}

Through the meshing of teeth with a conjugate profile, gears transfer mechanical power, in terms of torque and rotational speed, between two non-coaxial rotating shafts [1]. Nevertheless, the repeated sliding/rolling contact between the tooth flanks could lead to different fatigue failure modes [2]. For instance, high contact pressure can lead to damage in the meshing area such as wear, scuffing, pitting, and micro-pitting [1]. However, the most dangerous failure mode is due to the tooth root bending fatigue [3], [4]. Indeed, the transmitted forces during the meshing induce varying stresses on the tooth root fillet region that, in turn, potentially lead to cracks nucleation and propagation to the tooth root breakage [5].

In gear design, the prevention of the failure due to the tooth root bending fatigue is a primary objective [6] and it is supported by standards, e.g. (ISO 6336-3 [7] and ANSI/AGMA, 2001 [8]). To determine the load carrying capacity of a gear, standards suggest verifying (through specific calculation method) that the maximum stress $\sigma_{F}$ at the tooth root due to pure bending does not exceeds the permissible bending stress $\sigma_{F P}$. According to the Method B of ISO 6336-3 [7], $\sigma_{F P}$ is proportional to material strength $\sigma_{F l i m}$ that, in turn, is usually determined though experimental campaigns. 
To characterize $\sigma_{\text {Flim }}$ two types of tests can be carried out, i.e. tests on Running Gears (RG) [6], [9] and tests on Single Tooth Bending Fatigue (STBF) [10]-[13].

In $R G$ tests, test rigs have to be able to provide a given torque with proper lubrication to engaging RG [8], [14]. The specimen consists of a gear made of the material (and the treatments/finishes) to be tested. The specimen engages with one or more gears and, when a tooth breaks, the number of times the tooth has meshed is noted, and the entire specimen is replaced. Therefore, RG tests are able to reproduce the exact stress state of the actual gears and allow obtaining reliable value of $\sigma_{\text {Flim }}$ [15]. However, as a drawback, the experimental campaign results particularly long and expensive.

As for RG tests, also in STBF tests the specimen consists of a gear made of the material to be tested. In these configuration, pulsating forces are applied to two teeth of the same specimen through two anvils. Exploiting the Wildhaber property, these forces are tangent to the base circumference and normal to the tested teeth flanks. STBF tests can be performed on universal testing machine (which does not require lubrication of the sample) and multiple tests on a single specimen can be carried out since the forces are applied to two teeth per test. As a drawback, experimental evidences have shown that the results of STBF tests tend to overestimate the value of $\sigma_{\text {Flim }}$ [16], [17]. This is due to the different stress histories that RG and STBF induces on the tooth root witch were neglected by the standards [18].

Indeed, the stress histories at the tooth root differ for the following reasons. First, in STBF tests, for keeping the specimen in the right place during the test, a compressive load should be always present; the typical ratio between the minimum and maximum force applied to the teeth is $\mathrm{R}=0.1$, e.g. the STBF tests conducted in [14], [19]-[23]. Naturally, this differs from $\mathrm{RG}$ where $\mathrm{R}=0$ and, therefore, it modifies the mean stress [9], [11], [24], [25]. Second, in STBF tests, the forces are applied with a fixed direction and position and vary in a sinusoidal way with a constant amplitude while, in RG tests, both the force magnitude and direction are variable. In addition, the force direction in STBF tests can be different from the one in the Outer Point of Single pair tooth Contact (OPSC) of RG and, therefore, a different share between pure bending and pure compressive stresses could be present. Moreover, in RG tests, the variable number of mating teeth pairs leads to an uneven force sharing [26]. Consequently, the stress time history at the tooth root is not sinusoidal as in the STBF tests [9], [11].

To compensate these effects, a correction coefficient $\left(f_{\text {korr }}\right)$ can be exploited. $f_{\text {korr }}$ is representative of the ratio between the $\sigma_{\text {Flim }}$ obtained via STBF and the $\sigma_{\text {Flim }}$ obtained via $\mathrm{RG}$ (when the two tests were set to produce the same $\sigma_{F}$ according to the standard (ISO 6336-3)). This coefficient has been estimated experimentally by Rettig [16] and Stahl [17]. They proposed to exploit a constant value of $f_{\text {korr }}=0.9$. However, tests were conducted for a limited combination of materials and geometries and, therefore, new techniques to estimate $f_{\text {korr }}$ for each specific combination of material and geometry have been developed. An advanced method is presented in [26], where the scholars have combined the Crossland fatigue criterion [27] with a numerical simulation of RG and the experimental results of STBF tests. In this case, the corrective factors have resulted equal to 0.82 and 0.84 for the two materials tested. In the present paper, an innovative approach to calculate $f_{\text {korr }}$ through the combination of numerical simulations and fatigue criteria capable to take into account the different stress histories emerging in RG and STBF tests has been proposed. In particular, the main fatigue criteria based on the critical plane have been considered in this work. This approach has been implemented on a gear geometry previously tested by the authors' research group [28]. 


\section{BACKGROUND}

In the present section, an overview of the main fatigue criteria based on critical plane (i.e. Findley [29], Matake [30], McDiarmid [31], Papadopoulos [32], and Susmel et al. [33] exploited in this work is presented.

Having the stress histories (in term of stress tensors) referred to a specific point (eqn (1)) it is possible to evaluate the maximum octahedral stress $\sigma_{h, \max }$ (in the time window $T$ ) according to eqn (2). Where $\boldsymbol{\sigma}_{\boldsymbol{O}}$ is a vector containing the principal stresses that, for the same time instant $t$, satisfies eqn (3), the relation, where $\overline{\bar{I}}$ is the identity matrix.

In addition, it is possible to calculate the stress vector $\boldsymbol{P}_{\boldsymbol{n}}$ acting on a plane defined by a normal vector $\boldsymbol{n}\left(\phi_{n}, \theta_{n}\right)$ through the relation showed in eqn (4). The modulus and the direction of $\boldsymbol{P}_{\boldsymbol{n}}$ vary in time (Fig. 1(a)). In addition, $\boldsymbol{P}_{\boldsymbol{n}}$ can be decomposed into a normal component $\boldsymbol{\sigma}_{\boldsymbol{n}}$ (eqn (5)), having time-varying modulus and fixed direction, and a tangential component $\boldsymbol{\tau}_{\boldsymbol{n}}$, having time-varying modulus and direction that, in turn, can be decomposed in its component aligned with the $\boldsymbol{u}$ and $\boldsymbol{v}$ directions (eqn (6)) (Fig. 1(b)). Where $\boldsymbol{n}, \boldsymbol{u}, \boldsymbol{v}$ are defined in eqn (7).

$$
\begin{gathered}
\overline{\overline{\boldsymbol{\sigma}}}(t)=\left[\begin{array}{lll}
\sigma_{x x}(t) & \tau_{x y}(t) & \tau_{x z}(t) \\
\tau_{y x}(t) & \sigma_{y y}(t) & \tau_{y z}(t) \\
\tau_{z x}(t) & \tau_{z y}(t) & \sigma_{z z}(t)
\end{array}\right] \\
\sigma_{h, \text { max }}=\max _{T}\left\{\frac{1}{3} \sum_{i=1,2,3} \sigma_{O_{i}}\right\} \\
\operatorname{det}\left|\overline{\overline{\boldsymbol{\sigma}}}(\boldsymbol{t})-\boldsymbol{\sigma}_{\boldsymbol{O}} \overline{\overline{\boldsymbol{I}}}\right|=0, \\
\boldsymbol{P}_{\boldsymbol{n}}\left(\phi_{n}, \theta_{n}, t\right)=\overline{\overline{\boldsymbol{\sigma}}}(t) \boldsymbol{n}\left(\phi_{n}, \theta_{n}\right), \\
\boldsymbol{\tau}_{\boldsymbol{n}}\left(\phi_{n}, \theta_{n}, t\right)=\boldsymbol{u}^{T}\left(\phi_{n}, \theta_{n}\right) \overline{\overline{\boldsymbol{\sigma}}}(t) \boldsymbol{u}\left(\phi_{n}, \theta_{n}\right)+\boldsymbol{v}^{T}\left(\phi_{n}, \theta_{n}\right) \overline{\overline{\boldsymbol{\sigma}}}(t) \boldsymbol{v}\left(\phi_{n}, \theta_{n}\right), \\
\boldsymbol{n}\left(\phi_{n}, \theta_{n}\right)=\left[\begin{array}{c}
\cos \phi_{n} \sin \theta_{n} \\
\sin \phi_{n} \sin \theta_{n} \\
\cos \theta_{n}
\end{array}\right] ; \boldsymbol{u}\left(\phi_{n}, \theta_{n}\right)=\left[\begin{array}{c}
-\sin \theta_{n} \\
\cos \phi_{n} \\
0
\end{array}\right] ; \boldsymbol{v}\left(\phi_{n}, \theta_{n}\right)=\left[\begin{array}{c}
-\cos \phi_{n} \cos \theta_{n} \\
-\sin \phi_{n} \cos \theta_{n} \\
\sin \theta_{n}
\end{array}\right] .
\end{gathered}
$$

For periodic stresses, $\boldsymbol{P}_{\boldsymbol{n}}$ describes a closed curve in the space and, therefore, $\boldsymbol{\tau}_{\boldsymbol{n}}$ describes a closed curve in the plane. This curve is called as $\Gamma_{n}$ (Fig. 1(b)). With respect to $\sigma_{n}$, along the period $T$, it assumes different values from a minimum $\sigma_{n, \min }$ to a maximum $\sigma_{n, \max }$ (Fig. 1(b)). Therefore, it is possible to define the value of the alternating stress (acting on the plane having normal $\boldsymbol{n}) \sigma_{n, a}$ according to eqn (8).

$$
\sigma_{n, a}=\max _{T}\left\{\boldsymbol{\sigma}_{\boldsymbol{n}}(t)\right\}-\min _{T}\left\{\boldsymbol{\sigma}_{\boldsymbol{n}}(t)\right\}=\sigma_{n, \max }-\sigma_{n, \min } .
$$

The curve $\Gamma_{n}$ is representative of the tangential stresses acting on the studied plane during the entire loading cycle. To translate $\Gamma_{n}$ into a value of alternate tangential stress (exerting on the plane with normal $\boldsymbol{n}) \tau_{n, a}$ several methods can be found in the literature. The most diffused method is the Minimum Circumscribed Circle (MCC) (eqn (9)) [34], i.e. $\tau_{n, a}$ is calculated as the radius of the smallest circle that can entirely contain the curve $\Gamma_{n}$ (Fig. 2). 


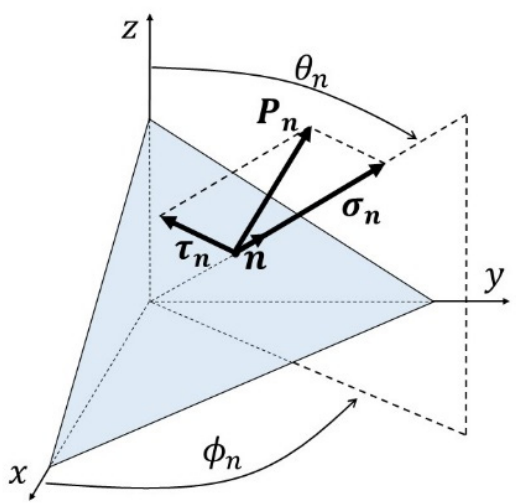

a)

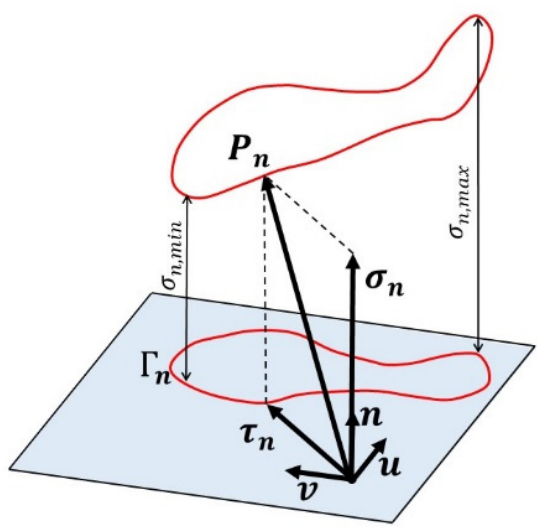

b)

Figure 1: (a) Components of $\boldsymbol{P}_{\boldsymbol{n}}\left(\phi_{n}, \theta_{n}, t\right)$ on the plane $\boldsymbol{n}\left(\phi_{n}, \theta_{n}\right)$; and (b) Definition of the curve $\Gamma_{n}$.

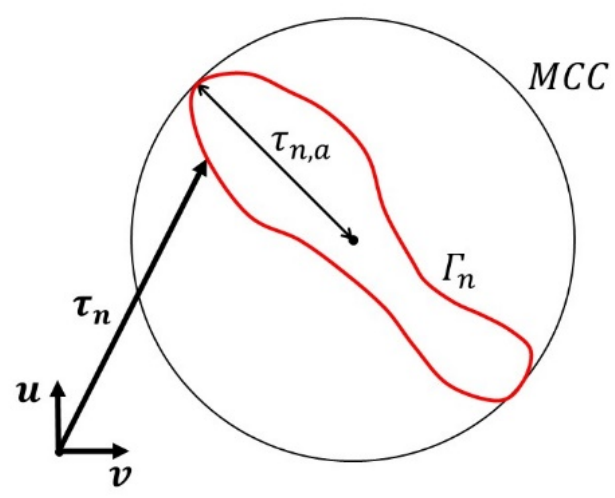

Figure 2: Minimum Circumscribed Circle (MCC) method.

$$
\tau_{n, a}=\underset{T}{\operatorname{MC}}\left\{\left\{\boldsymbol{\tau}_{\boldsymbol{n}}(t)\right\}\right.
$$

For each plane (having normal $\boldsymbol{n}$ ), that can be defined by varying the parameters $\left(\phi_{n}, \theta_{n}\right)$, it is possible to calculate the relevant stress parameters, i.e. $\tau_{n, a}, \sigma_{n, \max }$, and $\sigma_{n, a}$. More specifically, for the critical plane, the corresponding spherical coordinates and the related stresses will be labelled with the subscript $c$, i.e. $\phi_{c}, \theta_{c}, \tau_{c, a}, \sigma_{c, \text { max }}$, and $\sigma_{c, a}$.

The damage parameter of each fatigue criterion based on the critical plane can be represented as in eqn (10). In eqn (10), the parameter $k$ is a constant related to the material properties and $S$ is a variable related to the normal stresses exerting on the critical plane. Both of them varies according to the fatigue criterion in question. A summary of how the $k$ and $S$ parameters are defined based on the different fatigue criteria can be found in eqns (11)-(15). 
In particular, it is possible to notice that for the calculation of the parameter $k$ according to the McDiarmid criterion, the stress-rupture $\sigma_{R}$ is involved. For the other fatigue criteria, $k$ can be calculated through the material fatigue limit at symmetrical alternating bending loading $\left(\sigma_{f}\right)$, and the material fatigue limit at symmetrical alternating torsional loading $\left(\tau_{f}\right)$. With respect to the variable $S$, the Papadopoulos criterion considers the maximum octahedral stress $\sigma_{h, \max }$ while, the others, consider stresses related to the critical plane, i.e. $\sigma_{c, \max }$ in Finley and McDiarmid, $\sigma_{c, a}$ in Matake, and $\sigma_{c, \max } / \tau_{c, a}$ in Susmel et al.

$$
\begin{gathered}
D P=\tau_{c, a}+k S, \\
D P_{\text {Findley }}=\tau_{c, a}+\frac{2 r_{\tau / \sigma}-1}{2\left(\sqrt{r_{\tau / \sigma}-r_{\tau / \sigma}^{2}}\right)} \sigma_{c, \max }, \\
D P_{\text {Matake }}=\tau_{c, a}+\left(2 r_{\tau / \sigma}-1\right) \sigma_{c, a}, \\
D P_{\text {Susmel et al. }}=\tau_{c, a}+\left(\tau_{f}-\frac{\sigma_{f}}{2}\right) \frac{\sigma_{c, \max }}{\tau_{c, a}}, \\
D P_{\text {Papadopoulos }}=\tau_{c, a}+\left(\frac{3}{2}\left(2 r_{\tau / \sigma}-1\right)\right) \sigma_{h, \max }, \\
D P_{\text {McDiarmid }}=\tau_{c, a}+\frac{\tau_{f}}{2 \sigma_{R}} \sigma_{c, \max },
\end{gathered}
$$

where

$$
r_{\tau / \sigma}=\tau_{f} / \sigma_{f}
$$

The determination of the critical plane $\left(\phi_{c}, \theta_{c}\right)$ differs for the different fatigue criteria. For the Findley criterion, the critical plane is the plane on which the damage parameter assumes its maximum value (eqn (17)) while, for the other fatigue criteria, the critical plane coincides with the plane on which the $\tau_{c, a}$ assumes its maximum value (eqn (18)). Therefore, the application of the Findley criterion could lead to the identification of a critical plane having a different orientation with respect to the critical plane found applying the other fatigue criteria.

$$
\begin{gathered}
\left(\phi_{C}, \theta_{C}\right) \rightarrow \max _{\phi, \theta}\left\{\tau_{n, a}(\phi, \theta)+k S(\phi, \theta)\right\}, \\
\left(\phi_{C}, \theta_{C}\right) \rightarrow \max _{\phi, \theta}\left\{\tau_{n, a}(\phi, \theta)\right\} .
\end{gathered}
$$

\section{MATERIAL AND METHOD}

\subsection{Presentation of the general approach}

The concept behind the proposed approach is to simulate, for the same geometry, the STBF and the RG conditions with applied loads that lead, according to [6], to the same $\sigma_{\text {Flim }}$. Hence, through the results of the Finite Element (FE) models, it is possible to obtain the stresses histories (in terms of stress tensors $\overline{\overline{\boldsymbol{\sigma}}}(t)$ ) for all the nodes $N$ in the tooth root fillet 
region, i.e. each point where fracture could nucleate. Therefore, by analyzing the stress histories through a fatigue criterion based on a critical plane, it is possible to:

1. Individuate the critical plane for each point $\left(\theta_{c} \phi_{c}(N)\right)$;

2. Evaluate the damage parameter in each critical plane (eqn (10) applied on each node); and

3. Identify the critical point in which the damage parameter assumes the maximum value $\left(\max _{N}\left\{\left(\tau_{c, a}+k S\right)\right\}\right)$.

This process can be followed for the RG and the STBF simulations. The ratio between the maximum damage parameter emerged in the STBF condition and the one observed for the RG condition corresponds to the $f_{\text {korr }}$ as it represents the ratio between the different effects that cause failure for tooth bending failure (eqn (19)). The overall approach can be carried out by applying different fatigue criteria. More detail on the FE simulations and on the implementation of the above-mentioned fatigue criteria can be found in the following sections.

$$
f_{\text {korr }}=\frac{\left.\max _{N}\left\{\left(\tau_{c, a}+k S\right)\right\}\right|_{S T B F}}{\left.\max _{N}\left\{\left(\tau_{c, a}+k S\right)\right\}\right|_{R G}} .
$$

\subsection{Finite element analysis}

In the present work, the gear geometry presented in [28] has been modelled in both the RG and STBF conditions. Through KISSsoft ${ }^{\circledR}$ a CAD model of the gear (having the parameters listed in Table 1) has been realized. Hence, this model was imported into the open source FE software Salome-Meca/Code_Aster where the RG and STBF conditions have been numerically reproduced.

Table 1: Geometrical parameter of the simulated gear according to [28].

\begin{tabular}{|l|c|c|c|}
\hline Description & Symbol & Unit & Value \\
\hline Normal module & $m_{n}$ & {$[\mathrm{~mm}]$} & 4 \\
\hline Normal pressure angle & $\alpha_{n}$ & {$\left[{ }^{\circ}\right]$} & 20 \\
\hline Number of teeth & $z$ & {$[-]$} & 28 \\
\hline Face width & $b$ & {$[\mathrm{~mm}]$} & 30 \\
\hline Profile shift coefficient & $x$ & {$[-]$} & 0 \\
\hline Dedendum coefficient & $h_{f P}^{*}$ & {$[-]$} & 1.25 \\
\hline Root radius factor & $\rho_{f P}^{*}$ & {$[-]$} & 0.38 \\
\hline Addendum coefficient & $h_{a P}^{*}$ & {$[-]$} & 1 \\
\hline
\end{tabular}

In the FE model, symmetries were exploited to reduce the computational effort. In particular, in STBF simulations a quarter of each gear has been meshed while in the RG ones the whole gear profile has been modelled for half of the width. For each model, an extruded mesh was created. The quality of the mesh has been improved in teeth subjected to loads. More specifically, in that region the mesh density was increased and hexahedral elements have been exploited (Fig. 3). Non-linear simulations have been carried out setting 40 timesteps (along the period $T$ ) for loading cycle. 


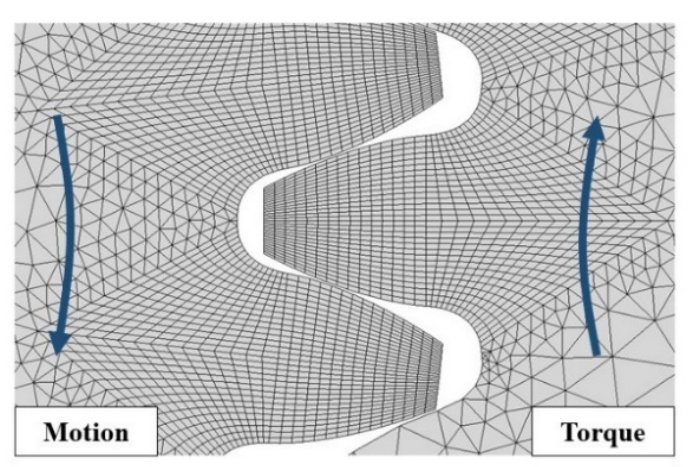

a)

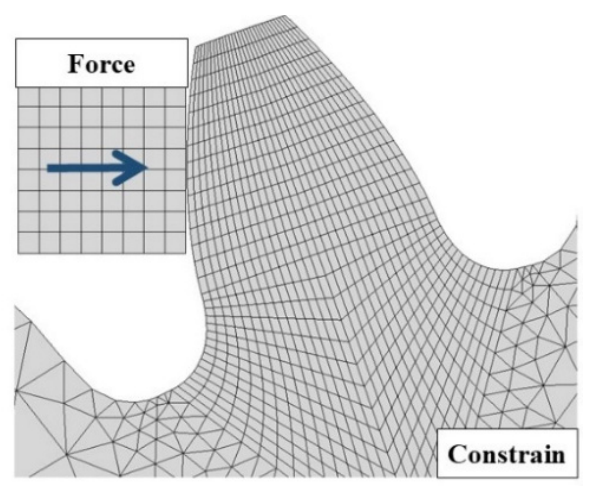

b)

Figure 3: Finite element models of (a) RG; and (b) STBF tests.

The model of the RG and STBF configurations are represented in Fig 1(a) and 1(b) respectively. In $\mathrm{RG}$, the engaging gears were positioned with the appropriate center distance and the axes of rotation were fixed. The motion was assigned to the driving gear and a resistant torque to the driven once. In STBF, the radial symmetry was exploited and a pulsating force with $\mathrm{R}=0.1$ was applied to the anvil. In particular, the force (in STBF) and the torque (in RG) have been set in order to lead to the same $\sigma_{F}$ according to the standard ISO 6336-3 [6]. Typical steels properties have been applied to the components. For each simulation, the $\overline{\overline{\boldsymbol{\sigma}}}(t)$ in the nodes in the tooth root fillet region have been extracted.

\subsection{Framework to calculate $f_{\text {korr }}$ applying different fatigue criteria}

Since the FE simulations were performed by setting the properties of steels in the linear elastic range, the results (in terms of $\overline{\overline{\boldsymbol{\sigma}}}(t)$ ) can be used to analyze any steel. In this case, three steels were analyzed (i.e. $18 \mathrm{NiCrMo5}, 42 \mathrm{CrMoS} 4$, and $31 \mathrm{CrMo} 12$ ) since these steels were also exploited in the gears tested in [28]. In Table 2, it is possible to see the fatigue limits (according to [35]) and the rupture stresses (according to [28]). These data were elaborated to calculate the parameter $k$ according to the various fatigue criteria through the formulas shown in eqns (11) to (15). Preliminary results are provided in Table 2.

Table 2: Constants related to the material properties.

\begin{tabular}{|l|c|c|c|c|c|c|c|c|}
\hline \multirow{2}{*}{ Material } & \multirow{2}{*}{$\sigma_{f}$} & \multirow{2}{*}{$\tau_{f}$} & \multirow{2}{*}{$\sigma_{R}$} & \multicolumn{5}{|c|}{$k$ according to } \\
\cline { 5 - 9 } & & & & Findley & Matake & Susmel & Papad. & McDiar. \\
\hline 18NiCrMo5 & 660.7 & 342.7 & 1467 & 0.037 & 0.037 & 12.350 & 0.056 & 0.117 \\
\hline 42CrMoS4 & 525.7 & 336.3 & 1160 & 0.291 & 0.279 & 73.450 & 0.419 & 0.145 \\
\hline 31CrMo12 & 628.3 & 366.6 & 987 & 0.169 & 0.167 & 52.450 & 0.250 & 0.186 \\
\hline
\end{tabular}

The $f_{\text {korr }}$ (according with the different fatigue criteria) have been calculated following the workflow presented in Fig. 4. 


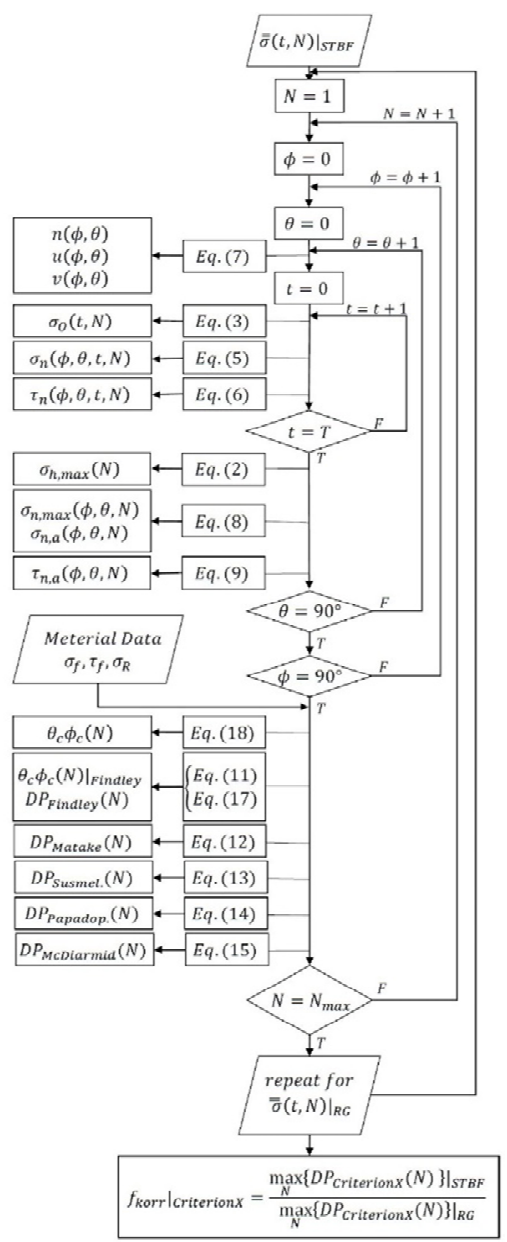

Figure 4: Framework to calculate $f_{\text {korr }}$ according to the different fatigue criteria.

For each simulation, the workflow is structured with four FOR loops. The innermost one analyses data along the time from time 0 to the end of cycle $\mathrm{T}$ for each time step recorded. The FOR loops on $\theta$ and $\phi$ aim to discretize the space of potential critical planes, in this case with a resolution of one degree. The FOR loop on the nodes (in this case 16 nodes within the tooth root fillet i.e. $N_{\max }=16$ ), aims to identify the most stressed node according to the various fatigue criteria. Eventually, the $f_{\text {korr }}$ (calculated based on the implementation of a specific fatigue criterion) have been calculated through the ratio between the maximum value of the damage parameter recorded in STBF nodes and the ones emerged in RG nodes.

\section{RESULTS AND DISCUSSION}

The results of the implementation of the proposed approach, in terms of $f_{\text {korr }}$ at varying fatigue criterion and material, are summarized in Table 3 . The results underline that, for the studied geometry, the application of the Susmel et al. criterion generally leads to higher values of $f_{\text {korr }}$ (ranging from 0.87 to 0.99 ) while the application of the Matake criterion leads 
to lower values of $f_{\text {korr }}$ (ranging from 0.77 to 0.79 ). With respect to the studied materials, the Matake and the McDiarmid show the lower variability of $f_{\text {korr }}$. On the other hand, the Findley and the Susmel et al. criterion show the greater variability. Therefore, the application of different fatigue criteria on the same gear (in terms of geometry and material) lead to different results. In particular, the maximum variability occurs for $42 \mathrm{CrMoS} 4$ where $f_{\text {korr }}$ ranges from 0.77 to 0.99 .

Table 3: $f_{\text {korr }}$ calculated through different combinations of materials and fatigue criteria.

\begin{tabular}{|l|c|c|c|c|c|}
\hline \multirow{2}{*}{ Material } & \multicolumn{5}{|c|}{$f_{\text {korr }}$ according to } \\
\cline { 2 - 6 } & Findley & Matake & Susmel et al. & Papadopoulos & McDiarmid \\
\hline 18NiCrMo5 & 0.81 & 0.79 & 0.87 & 0.81 & 0.83 \\
\hline 42CrMoS4 & 0.91 & 0.77 & 0.99 & 0.86 & 0.83 \\
\hline 31CrMo12 & 0.86 & 0.78 & 0.97 & 0.84 & 0.84 \\
\hline
\end{tabular}

Further considerations can be made based on the results shown in Fig. 5. In Fig. 5, the critical plane passing through the critical node has been reported for RG and STBF conditions. In the figure, the fifteen combination of material and fatigue criterion studied are reported. In all these combinations, the angle $\theta_{c}$ has resulted $90^{\circ}$. Therefore, it has been possible to report the solutions in a two-dimensional representation.

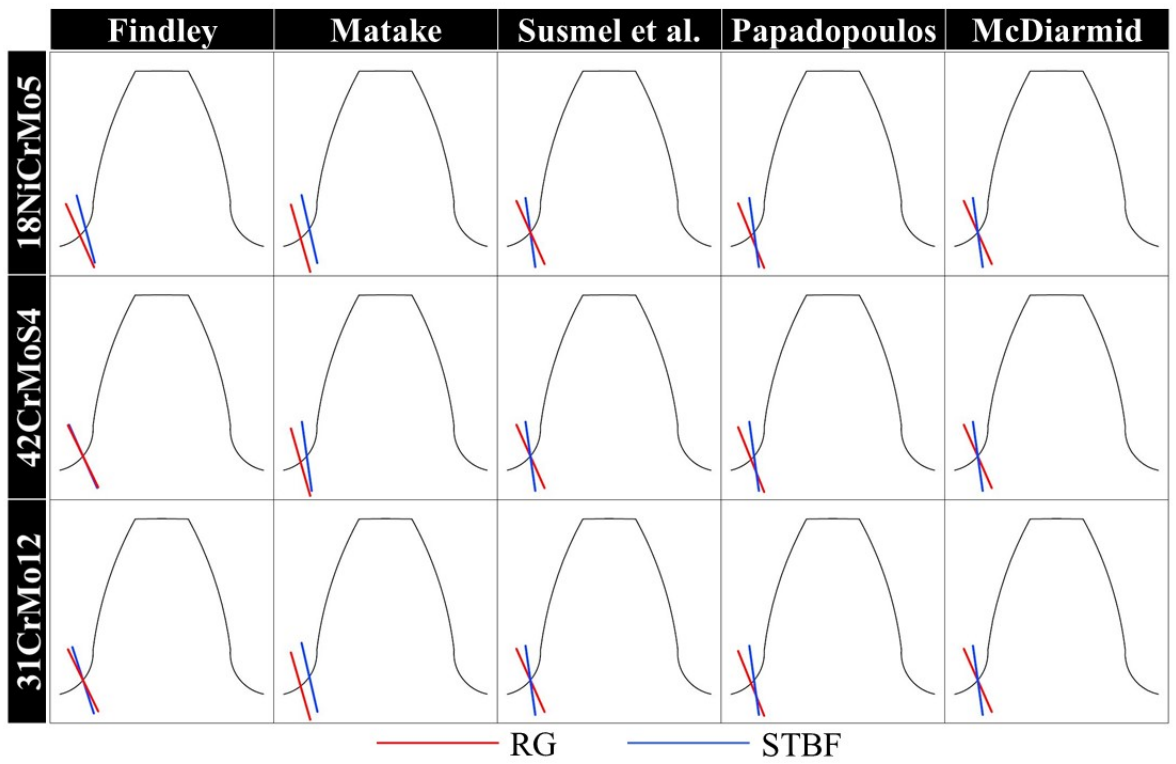

Figure 5: Comparison between the critical planes emerged for RG and STBF for different material-criterion combinations.

It is worth noting that the critical node in the STBF condition can be different from the critical node in the RG condition. If this occurs (i.e. Findley-18NiCrMo5, Matake and Papadopoulos for all materials), the critical node related to the STBF condition is located 
closer to the meshing area than the critical node related to the RG condition. Moreover, it is possible to notice that the Matake criterion lead to the largest discrepancy, in terms of critical node location, between the RG and STBF conditions. Furthermore, the results clearly highlight that, in the RG condition, the angle between the critical plane and the tooth axis is always greater than in STBF condition.

\section{CONCLUSIONS}

In conclusion, this paper describes an approach to calculate a coefficient $\left(f_{\text {korr }}\right)$ that enables the translation of STBF test results into usable data for gear design. This approach proposes to analyse the results of FE simulations (which aim to represent STBF and RG conditions leading to the same $\sigma_{F}$ according to ISO 6336) with different fatigue criteria based on the critical plane. In particular, the implementation of these fatigue criteria requires data on specific material properties (i.e. $\tau_{f}, \sigma_{f}$, and $\sigma_{R}$ ) that can be obtained from standard tests or from literature. Moreover, through the implementation of this approach, it is possible to obtain the position of the most critical node and the orientation of its critical plane for each simulated condition.

This approach was applied to a specific gear geometry exploited in previous studies by the authors' research group. In addition, the application of different fatigue criteria (i.e. Findley, Matake, McDiarmid, Papadopoulos, and Susmel et al.) as well as different materials (i.e. $18 \mathrm{NiCrMo} 5,42 \mathrm{CrMoS} 4$, and $31 \mathrm{CrMo} 12$ ) have been investigated in this paper.

Results show that the fatigue criterion exploited has a considerable impact on the value of $f_{\text {korr }}$. Therefore, for the purpose of this paper, the fatigue criteria are not equivalent to each other. Future studies should aim to investigate which fatigue criterion is the most appropriate.

\section{REFERENCES}

[1] Vullo, V., Gears, Springer International Publishing, 2020.

[2] Radzevich, S.P. \& Dudley, D.W., Handbook of Practical Gear Design, CRC Press, 1994.

[3] Fernandes, P.J.L., Tooth bending fatigue failures in gears. Engineering Failure Analysis, 3(3), pp. 219-225, 1996. DOI: 10.1016/1350-6307(96)00008-8.

[4] Pantazopoulos, G.A., Bending fatigue failure of a helical pinion bevel gear. Journal of Failure Analysis and Prevention, 15(2), pp. 219-226, 2015.

DOI: $10.1007 / \mathrm{s} 11668-015-9947-2$.

[5] Bretl, N., Schurer, S., Tobie, T., Stahl, K. \& Höhn, B.R., Investigations on tooth root bending strength of case hardened gears in the range of high cycle fatigue. American Gear Manufacturers Association Fall Technical Meeting, pp. 103-118, 2013.

[6] Hong, I.J., Kahraman, A. \& Anderson, N., A rotating gear test methodology for evaluation of high-cycle tooth bending fatigue lives under fully reversed and fully released loading conditions. International Journal of Fatigue, 133, p. 105432, 2020. DOI: $10.1016 / j$.ijfatigue.2019.105432.

[7] ISO 6336-3:2006, Calculation of Load Capacity of Spur and Helical Gears, Part 3: Calculation of Tooth Bending Strength, Standard: Geneva, CH, 2006.

[8] ANSI/AGMA 2001-D04, Fundamental Rating Factors and Calculation Methods for Involute Spur and Helical Gear Teeth, American Gear Manufacturers Association: Alexandria, 2004.

[9] Rao, S.B. \& McPherson, D.R., Experimental characterization of bending fatigue strength in gear teeth. Gear Technology, 20(1), pp. 25-32, 2003. 
[10] Benedetti, M., Fontanari, V., Höhn, B.R., Oster, P. \& Tobie, T., Influence of shot peening on bending tooth fatigue limit of case hardened gears. International Journal of Fatigue, 24(11), pp. 1127-1136, 2002. DOI: 10.1016/S0142-1123(02)00034-8.

[11] McPherson, D.R. \& Rao, S.B., Methodology for translating single-tooth bending fatigue data to be comparable to running gear data. Gear Technology, pp. 42-51, 2008.

[12] Dobler, D.I.A., Hergesell, I.M. \& Stahl, I.K., Increased tooth bending strength and pitting load capacity of fine-module gears. Gear Technology, 33(7), pp. 48-53, 2016.

[13] Concli, F., Tooth root bending strength of gears: Dimensional effect for small gears having a module below $5 \mathrm{~mm}$. Applied Science, 11, p. 2416, 2021.

DOI: 10.3390/app11052416.

[14] Gorla, C., Conrado, E., Rosa, F. \& Concli, F., Contact and bending fatigue behaviour of austempered ductile iron gears. Proceedings of the Institution of Mechanical Engineers, Part C: Journal of Mechanical Engineering Science, 232(6), pp. 998-1008, 2018. DOI: $10.1177 / 0954406217695846$.

[15] McPherson, D.R. \& Rao, S.B., Mechanical Testing of Gears, ASM International: Materials Park, OH, pp. 861-872, 2000.

[16] Rettig, H., Ermittlung von Zahnfußfestigkeitskennwerten auf Verspannungsprüfständen und Pulsatoren-Vergleich der Prüfverfahren und der gewonnenen Kennwerte. Antriebstechnik, 26, pp. 51-55, 1987.

[17] Stahl, K., Lebensdauer statistik: Abschlussbericht, forschungsvorhaben nr. 304. Technical Report, 580, 1999.

[18] Concli, F., Fraccaroli, L. \& Maccioni, L., Gear root bending strength: A new multiaxial approach to translate the results of single tooth bending fatigue tests to meshing gears. Metals, 11(6), p. 863. DOI: 10.3390/met11060863.

[19] Concli, F., Austempered Ductile Iron (ADI) for gears: Contact and bending fatigue behavior. Procedia Structural Integrity, 8, pp. 14-23, 2018.

DOI: 10.1016/j.prostr.2017.12.003.

[20] Bonaiti, L., Concli, F., Gorla, C. \& Rosa, F., Bending fatigue behaviour of 17-4 PH gears produced via selective laser melting. Procedia Structural Integrity, 24, pp. 764 774, 2019. DOI: 10.1016/j.prostr.2020.02.068.

[21] Gasparini, G., Mariani, U., Gorla, C., Filippini, M. \& Rosa, F., Bending 367 fatigue tests of helicopter case carburized gears: Influence of material, design 368 and manufacturing parameters. American Gear Manufacturers Association 369 (AGMA) Fall Technical Meeting, pp. 131-142, 2008.

[22] Gorla, C., Rosa, F., Concli, F. \& Albertini, H., Bending fatigue strength of innovative gear materials for wind turbines gearboxes: Effect of surface coatings. ASME International Mechanical Engineering Congress and Exposition, vol. 45233, American Society of Mechanical Engineers, pp. 3141-3147, 2012.

DOI: 10.1115/IMECE2012-86513.

[23] Gorla, C., Rosa, F., Conrado, E. \& Concli, F., Bending fatigue strength of case carburized and nitrided gear steels for aeronautical applications. International Journal of Applied Engineering Research, 12(21), pp. 11306-11322, 2017.

[24] Rao, S.B., Schwanger, V., McPherson, D.R. \& Rudd, C., Measurement and validation of dynamic bending stresses in spur gear teeth. International Design Engineering Technical Conferences and Computers and Information in Engineering Conference, vol. 4742, pp. 755-764, 2005. DOI: 10.1115/DETC2005-84419.

[25] Wagner, M., Isaacson, A., Knox, K. \& Hylton, T., Single tooth bending fatigue testing at any $\mathrm{R}$ ratio. 2020 AGMA/ABMA Annual Meeting, AGMA American Gear Manufacturers Association, 2020. 
[26] Bonaiti, L., Bayoumi, A.B.M., Concli, F., Rosa, F. \& Gorla, C., Gear root bending strength: A comparison between single tooth bending fatigue tests and meshing gears. Journal of Mechanical Design, pp. 1-17, 2021. DOI: 10.1115/1.4050560.

[27] Crossland, B., Effect of large hydrostatic pressures on the torsional fatigue strength of an alloy steel. Proceedings of the International Conference on Fatigue of Metals, vol. 138, Institution of Mechanical Engineers: London, pp. 12-12, 1956.

[28] Conrado, E., Gorla, C., Davoli, P. \& Boniardi, M., A comparison of bending fatigue strength of carburized and nitrided gears for industrial applications. Engineering Failure Analysis, 78, pp. 41-54, 2017. DOI: 10.1016/j.engfailanal.2017.03.006.

[29] Findley, W.N., A theory for the effect of mean stress on fatigue of metals under combined torsion and axial load or bending. Journal of Engineering for Industry, 81(4), pp. 301-305, 1959. DOI: 10.1115/1.4008327.

[30] Matake, T., An explanation on fatigue limit under combined stress. Bulletin of JSME, 20(141), pp. 257-263, 1977. DOI: 10.1299/jsme1958.20.257.

[31] McDiarmid, D.L., Fatigue under out-of-phase biaxial stresses of different frequencies. Multiaxial Fatigue, ASTM International, 1985. DOI: 10.1520/STP36245S.

[32] Papadopoulos, I.V., A high-cycle fatigue criterion applied in biaxial and triaxial outof-phase stress conditions. Fatigue \& Fracture of Engineering Materials \& Structures, 18(1), pp. 79-91, 1995. DOI: 10.1111/j.1460-2695.1995.tb00143.x.

[33] Susmel, L., Tovo, R. \& Lazzarin, P., The mean stress effect on the high-cycle fatigue strength from a multiaxial fatigue point of view. International Journal of Fatigue, 27(8), pp. 928-943, 2005. DOI: 10.1016/j.ijfatigue.2004.11.012.

[34] Papadopoulos, I.V., Critical plane approaches in high-cycle fatigue: On the definition of the amplitude and mean value of the shear stress acting on the critical plane. Fatigue \& Fracture of Engineering Materials \& Structures, 21(3), pp. 269-285, 1998. DOI: 10.1046/j.1460-2695.1998.00459.x.

[35] Susmel, L., On the overall accuracy of the modified Wöhler curve method in estimating high-cycle multiaxial fatigue strength. Frattura ed Integrita Strutturale, 5(16), pp. 5-17, 2011. DOI: 10.3221/IGF-ESIS.16.01. 